\title{
Pedagogia crítica da Educação Física: uma análise comparada entre o Brasil e a literatura anglófona
}

Felipe Quintão de Almeida ${ }^{a, *}$ (I)

Palavras Chave:

Pedagogia Crítica;

Educação Física;

Crítica Social;

Campo Científico.

\begin{abstract}
RESUMO
Este ensaio oferece uma análise comparada do desenvolvimento da pedagogia crítica no campo da Educação Física. Examina sua trajetória em duas diferentes paisagens cognitivas. Por um lado, a realidade brasileira e, por outro, a representada pela literatura anglófona. Em termos metodológicos, o estudo opera, como fonte, com importantes livros e revistas publicados nas últimas três décadas no Brasil e no mundo anglófono. Os resultados apontam para afinidades, mas, também, para diferenças na trajetória da pedagogia crítica nos dois universos investigados.
\end{abstract}

\section{Keywords:}

Critical Pedagogy; Physical Education; Social Critique; Scientific Field.

\section{Palavras Chave:} Pedagogía Crítica; Educación Física; Crítica Social; Campo Científico.

\begin{abstract}
This paper offers a comparative analysis of the recent development of critical pedagogy in the Physical Education field. The article examines the trajectory between two cognitive landscapes. On one hand, the Brazilian reality and, on the other hand, that which is represented by Anglophone literature. In methodological terms, the study has been sourced by important books and journals published in the last three decades, in Brazil and in the anglophone world. The results highlight similarities but, also, differences in the trajectory of socially critical scholarship in both investigated environments.
\end{abstract}

\begin{abstract}
RESUMEN
Este artículo ofrece un análisis comparativo sobre el desarrollo de la pedagogía crítica en el campo de la Educación Física. El texto examina su trayectoria en dos diferentes paisajes cognitivas. Por un lado, la realidad brasileña y, por otro, la representada por la literatura anglófona. En términos metodológicos, el estudio opera, como fuente, con importantes libros y revistas publicados en las últimas tres décadas, en el Brasil y en lo mundo anglófono. Los resultados apuntan para afinidades, pero, también, para diferencias en la trayectoria de la pedagogía crítica en los dos universos investigados.
\end{abstract}

a Universidade Federal do Espírito-Santo, Centro de Educação Física e Desportos, Departamento de Ginástica, Vitória, Espírito-Santo, Brasil.

*Autor correspondente:

Felipe Quintão de Almeida

E-mail: fqalmeida@hotmail.com

Recebido em 12 de abril de 2019; aceito em 11 de junho de 2019.

DOI: https://doi.org/10.1590/rbce.42.2019-097 


\section{INTRODUÇÃO ${ }^{1}$}

Neste ensaio, dou sequência às reflexões iniciadas em outro (Almeida, 2019), quando ofereci uma descrição da pedagogia crítica da Educação Física na literatura anglófona, ocasião para discutir suas origens teóricas, narrar seu desenvolvimento, (auto)críticas e perspectivas de futuro. Aqui, o exercício analítico coteja essa trajetória à luz da realidade brasileira, oportunidade para traçar afinidades, mas, também, ressaltar diferenças entre esses dois universos.

Em termos metodológicos, realizei uma investigação em livros reconhecidos e em periódicos renomados, no universo anglófono, que têm publicado, nos últimos 30 anos, textos de pedagogia crítica, como "Quest", "Sport, Education and Society", "Physical Education and Sport Pedagogy" e "European Physical Education Review". A escolha dessas revistas se justifica pois, segundo Devís-Devís (2006), elas tiveram um papel de destaque na divulgação dos preceitos da pedagogia crítica. Além disso, tive acesso ao conteúdo de todos os números publicados digitalmente. Como critério de sua qualidade, elas estão registradas nas mais importantes bases indexadores de periódicos científicos. No caso brasileiro, as análises são feitas com base em investigações realizadas em outros momentos (Bracht et al. 2011, 2012; Almeida, Bracht e Vaz, 2015), atualizadas com a leitura de livros e revistas que continuam divulgando a tradição sociocrítica da Educação Física no Brasil. Dentre elas, a "Revista Brasileira de Ciências do Esporte", a "Movimento", a "Motrivivência" e a "Pensar a Prática". Das fontes, priorizei a seleção e interpretação de artigos que, explicitamente, se reportavam a uma pedagogia crítica ou ao conhecimento socialmente crítico.

O ensaio está organizado em três sessões, seguidas das considerações finais.

\section{A INVENÇÃO DE UMA TRADIÇÃO...}

Umprimeiroaspectoadestacaréqueosanos 1980 foram decisivos para o surgimento das reflexões sociocríticas no âmbito das "duas" literaturas investigadas. Embora não se deva negar a existência de críticas à trajetória da Educação Física em anos anteriores, é consenso que, no Brasil, a década de 1980 viu surgir uma reflexão que se adjetivou, ela própria, de crítica. Como sobejamente conhecido, essas análises foram desencadeadas por um movimento que, retrospectivamente, ficou conhecido como renovador. De modo semelhante, também a década de 1980 viu surgir propostas renovadoras nos escritos em língua inglesa. Tais

\footnotetext{
${ }^{1}$ Apoio da Capes na modalidade de bolsa "professor visitante exterior júnior" (processo 88881.170970/2018-01). O autor declara não haver conflito de interesse.
}

produções críticas foram deflagradas em países distintos (como o Reino Unido, a Austrália, a Nova Zelândia e os Estados Unidos), que, em comum, possuíam não apenas a publicação em inglês, mas o desejo de contestar a tradição da Educação Física, redescrevendo-a.

No âmbito das "duas" literaturas investigadas, a tradição respondia por uma prática esportista, elitista, sexista, cientificista, tecnocrática, "iludida" com o culto da saúde e do corpo perfeito, carente de preocupações políticas, sociais e morais a respeito da prática pedagógica. Esta compreensão era sustentada por uma paisagem cognitiva que considerava o corpo como "natureza morta", que podia ser manipulado e aperfeiçoado graças, também, à intervenção do professor de Educação Física (Kirk, 1986, 1988; Bracht, 1986).

Ao mesmo tempo, essa leitura da tradição estava inserida no âmbito de um modo de teorizar a escola como lugar da reprodução social, mas, também, instituição que preservaria as condições de possibilidade de superação do status quo. Não surpreende, assim, encontrar, nos textos analisados, discursos em favor da conscientização, do empoderamento e da (auto) reflexão crítica com vistas à transformação social (Kirk, 1986, 1988; Bracht, 1986).

Como consequência, veio à tona uma literatura denunciando práticas ideológicas, acríticas, apolíticas, a-históricas, místicasealienantes(Taffarel,1990;Kirk,1988). Em seu lugar, o que se propôs foi uma pedagogia crítica, marcada pela historicidade e pela politização em favor do esclarecimento e da emancipação individual e coletiva por meio da escola. Nesse contexto, a criança que praticava esportes nas aulas de Educação Física não poderia continuar reproduzindo as regras do jogo capitalista (Bracht, 1986), o culto da magreza (Tinning, 1985) ou as ideologias (heathism, individualism and recreationalism) que dominavam a formação na Educação Física (George e Kirk, 1988). Era preciso, contra o passado, inventar uma nova tradição para a disciplina.

Apesar desse solo comum, o campo educacional mais amplo repercutiu de modo distinto na construção das pedagogias críticas. No Brasil, embora não exclusivamente, o desenvolvimento inicial de uma pedagogia crítica à Educação Física foi especialmente marcado pelo impacto da pedagogia marxista. ${ }^{2}$ Nesse contexto, um importante destaque precisa ser dado à pedagogia histórico-crítica, cujos traços definidores foram esboçados por Dermeval Saviani. ${ }^{2}$ Chamo de pedagogia marxista aquela perspectiva educacional
que, desde a década de 1980, fundamenta suas reflexões na
obra de Marx e na tradição que dela se desenvolveu. Tenho
clareza, todavia, que em Educação e na Educação Física, há
"marxismos" e "marxismos", de modo que este ensaio está
se referindo a uma determinada interpretação desta tradição. 
O principal resultado dessa influência foi a publicação da obra "Metodologia do ensino da Educação Física", popularmente conhecida como "Coletivo de autores", e sua concepção crítico-superadora. Essa perspectiva se colocou na contramão das chamadas teorias não-críticas da educação (pedagogia tradicional, pedagogia nova e pedagogia tecnicista) e suas diferentes repercussões na história da Educação Física.

É importante ressaltar, contudo, que alguns autores da área, quando do surgimento de tais perspectivas, foram influenciados por outras tradições teóricas ou, então, por perspectivas (auto)críticas no interior da própria tradição marxista. Este é o caso, por exemplo, do pioneiro trabalho de Elenor Kunz "Educação Física: ensino e mudanças", ao colocar em diálogo uma perspectiva fenomenológica do movimentar-se humano (Teoria do Se-Movimentar Humano) com a pedagogia de Paulo Freire $^{3}$ e a teoria do agir comunicativo de Jürgen Habermas. A partir de então, ficaram conhecidos, no Brasil, seus argumentos a respeito de uma pedagogia crítico-emancipatória.

Nos textos anglófonos, uma pedagogia crítica opunhase à visão cientificista, tecnicista e tradicional do currículo. Nesse contexto, é facilmente notável a influência de Paulo Freire na construção da perspectiva crítica da disciplina. Além disso, e contra as teorias tradicionais e conceituaisempiristas do currículo, autores educacionais identificados, naquele momento, com uma sociologia (da educação) neo ou pós-marxista, como Michel Apple, Michael Young, Peter Maclaren, Henry Giroux, etc. foram responsáveis por fornecer à Educação Física os fundamentos iniciais daquela pedagogia (Kirk, 1986, 1988). Como corolário, a literatura crítica em língua inglesa não experimentou, como no Brasil, um predomínio da pedagogia marxista em suas reflexões críticas iniciais. Some-se a isso o fato de a metodologia da pesquisa-ação, representada por nomes como Lawrence Stenhouse, Stephen Kemmis e Wilfred Car, ter influenciado os primeiros pedagogos críticos durante os anos 1980 (Kirk, 1986, 1988). No caso brasileiro, por sua vez, essa metodologia de investigação começou a ser empregada no início dos anos 2000 e, na atualidade, nem sempre seu uso está associado à perspectiva crítica da disciplina.

\section{DÚVIDA PÓS-MODERNA: COM OU CONTRA A PEDAGOGIA CRÍTICA?}

Outro aspecto interessante para cotejar as tradições críticas em análise é o tratamento conferido ao que Burbules (2000) chamou de dúvida pós-moderna em educação. Conforme demonstrado em outro artigo

\footnotetext{
${ }^{3}$ Paulo Freire é um pedagogo bastante influenciado pela tradição marxista, mas que absorveu outras perspectivas teóricas. Alguns comentadores identificam uma fase neomarxista e, mesmo, pósmoderna em seus escritos, o que indica o lugar "ambíguo" de Paulo Freire em relação à tradição dialética que tanto o inspirou.
}

(Almeida, 20199), o discurso sociocrítico da Educação Física, na literatura inglesa, não opôs a dúvida pósmoderna à agenda da pedagogia crítica. Ao contrário, a celeuma pós-moderna foi incorporada a seus discursos emancipadores. Há dezenas de textos que visam conciliar a pedagogia crítica com temas, questões, críticas, bem como a referências, como o pós-estruturalismo, que costumam ser associadas ao prefixo "pós". Na avaliação de Wright (2006), por exemplo, os livros Teachers, teaching and control in Physical Education (1988) e Physical education, curriculum and culture (1990), obras inaugurais da pedagogia crítica na literatura anglófona, já ofereceriam uma abordagem "pós" dessa tradição.

Uma consequência evidente do impacto provocado pelo pós-moderno ${ }^{4}$ na pedagogia crítica foi sua pluralização discursiva, o que levou o projeto crítico da disciplina a expandir a referência do que se pode considerar pedagogia crítica. Tal diversidade dificulta afirmar, com precisão, a diferença dessa tradição em relação a outras abordagens paradigmáticas. Tornou-se recorrente, neste caso, o uso da expressão big tent para se referir às múltiplas perspectivas do conhecimento socialmente crítico no âmbito da disciplina (Almeida, 2019). Esta situação levou a um quadro em que se verifica a existência de muitas versões da pedagogia crítica, que passa a ser caracterizada, no entender de Tinning (2010), pela reunião de perspectivas teóricas e metodológicas diversas, como a teoria crítica, a pesquisa-ação, o pósestruturalismo, o estudo de caso e o feminismo.

Situação diferente se passou em território brasileiro quanto à relação da pedagogia crítica com a dúvida pósmoderna. Para ser mais preciso, é possível identificar, pelo menos, três condutas.

A primeira delas ocorreu em forma de reação ao pós-modernismo e sua agenda, tida como conservadora, não emancipatória e até mesmo irracionalista. Em "defesa da história" e contra a "agenda pós-moderna". Foi deste modo que a pedagogia crítica marxista da Educação Física brasileira se comportou em relação à incredulidade pós-moderna. Assim o fez para, outra vez, justificar que a verdadeira leitura do real é a que reflete sua própria perspectiva (Taffarel; Albuquerque 2010; Gamboa, 2010). Essa reação encontra paralelos, diga-se de passagem, no campo educacional mais amplo.

Também vem da área da educação outra atitude em relação à incredulidade "pós". Inspirados por uma classificação que dividia as teorias curriculares em críticas e pós-críticas, muitos "curriculistas" brasileiros começaram a operar com o conceito de pedagogia pós-

${ }^{4}$ Essa expressão é aqui entendida como a incredulidade diante das metanarrativas; uma desconfiança com relação à crença no progresso das ciências e da razão como força emancipatória. Não significa, portanto, rejeição, refutação ou negação, mas uma incapacidade de acreditar "de uma vez por todas" (Burbules, 2000). 
crítica ${ }^{5}$ como resposta à incredulidade pós-moderna na educação. Embora vozes já tivessem ecoado nos anos 1990, anunciando o "adeus à Educação Física crítica" e o esgotamento das pedagogias radicais, só recentemente os argumentos em favor de uma pedagogia pós-crítica têm sido empregados no campo, sobretudo por Marcos Garcia Neira e seus colaboradores. Neste caso, assumese a caracterização que distingue a pedagogia crítica da pós-crítica, ao mesmo tempo em que se interpreta que determinados temas, como raça, etnia e gênero, não foram contemplados pela pedagogia crítica clássica. Esta ausência, diga-se de passagem, é uma situação que não reflete a realidade da pedagogia crítica no universo anglófono, pois as questões identitárias, como as acima mencionadas, constituem seu objeto de reflexão há algum tempo. ${ }^{6}$

Por fim, é possível identificar outro tipo de procedimento quanto ao impacto "pós". Neste caso, não se trata de ser contra a pedagogia crítica ou a favor dela, mas de praticar a atitude ambivalente de estar com ela, mas também contra ela, exercendo o direito à incredulidade posta pela dúvida pós-moderna. Neste caso, são os textos de Valter Bracht, sozinho ou com colaboradores, que melhor exemplificam essa conduta. É possível notar como Bracht foi incorporando à "sua" defesa do conhecimento socialmente crítico temas, dúvidas, questões e conceitos que são associados às perspectivas pós. Faz isso, todavia, numa direção semelhante à identificada no âmbito da literatura anglófona, ou seja, visando incorporar ao discurso emancipatório da pedagogia crítica as contribuições de autores tidos como pós-modernos, como Bauman e Rorty, ou, então, de referências (auto)críticas da própria modernidade iluminista, como Adorno, Gadamer, Habermas e Honneth. Renovar ou redescrever a pedagogia crítica é o resultado esperado por Bracht, uma vez reconhecida a dúvida pós-moderna na educação.

\section{(AUTO)CRÍTICAS, RENOVAÇÕES...}

Vozes dissonantes, internas e externas ao campo crítico, começaram a aparecer ainda nos anos 1990. Tanto no Brasil como na literatura anglófona, a pedagogia crítica foi censurada pelos dualismos que empregou em seus textos, o que produziu uma série de binarismos, como "bem/mal",

\footnotetext{
${ }^{5}$ Essa expressão é aqui empregada para se referir aos impactos provocados por teorias diversas, como o pós-estruturalismo, a teoria queer e feminista, os estudos multiculturais, pós-coloniais, étnicos, raciais, etc. na teorização curricular da Educação e da Educação Física. Um “mapa" dessa pedagogia pode ser encontrado em Paraíso (2004). ${ }^{6} \mathrm{Na}$ literatura anglófona também há menção a ideia de uma pedagogia pós-crítica no âmbito da Educação Física em dois textos de Judy Bruce, professora da Universidade de Canterbury, na Nova Zelândia. Apesar disso, não me parece uma tendência significativa naquele universo.
}

"direita/esquerda”, "social/biológico", "natureza/cultura”, "político/apolítico", "oculto/manifesto", "direita/esquerda, "crítico/conservador", "consciente/não-consciente", "ideológico/científico" etc., que resultou em "divisões" e incompreensões na área.

Também objeções foram levantadas contra uma compreensão de ideologia, entendida, por um lado, como oposta ao conhecimento científico e, por outro lado, como representação que ofusca ou oculta a realidade (George e Kirk, 1988; Kirk, 1988; Rigo e Chagas, 1990). Seria objetivo do conhecimento socialmente crítico desvelar essa realidade, mostrando como, de fato, ela "é" quando descoberta do véu ideológico. Uma compreensão, decerto, colocada sob suspeita (SicíliaCamacho e Fernández-Balboa, 2009; Almeida, Bracht e Vaz, 2015), pois baseada num realismo forte, que distingue, ao menos, dois níveis de compreensão da realidade social: um mais profundo e, portanto, mais verdadeiro, e outro superficial e, desta maneira, falso. Quanto mais "vertical" e penetrante a compreensão de algo (do que a Educação Física "é"), mais afastada está da aparência e mais perto da realidade. Em tais circunstâncias, o discurso sociocrítico foi acusado de ser autoconfiante, dogmático, legislador, dotado de uma moral (universalista) superior quando comparado aos demais (Bracht e Almeida, 2008; O'Sullivan, Siendetop e Locke, 1992; Sicília-Camacho e Fernández-Balboa, 2009).

Em tais circunstâncias, Tinning $(2002,2010)$ cunhou a expressão "pedagogia modesta" para se contrapor à compreensão de um conjunto de procedimentos pedagógicos que, quando encontrados, levarão à certeza em relação à "entrega" de certos resultados (emancipatórios ou conservadores). Como forma de se precaver das "armadilhas" em que o pensamento crítico se envolveu, "We need to be modest in our claims for what can be achieved in the critical classroom and gymnasium and we should seek to develop forms of pedagogy that are more modest than certain" (Tinning, 2010, p. 121).

Esse conceito de pedagogia modesta é compatível com o argumento - defendido por Bracht (2016) - de que apenas uma forma "débil" ou "fraca" de crítica, ligada aos contextos (a pessoas, portanto) é desejável na atual paisagem cognitiva. Isto pressupõe deixar de operar com uma noção de crítica baseada num realismo forte, que postula a noção da verdade como correspondência com a realidade, já que subjaz a essa compreensão a ideia de que um dia seria possível penetrar na matriz verdadeira, natural e a-histórica de toda linguagem e conhecimento possíveis. Ao contrário, uma forma "fraca" de crítica implica a adoção de uma humildade epistemológica frente ao fato de que nossa relação com o conhecimento não tem fundamentos indubitáveis capazes de eliminar, de uma vez por todas, 
a incerteza e a contingência do mundo. Dito de outro modo, esse modo de compreender a crítica é expressão de sua passagem da esfera da legislação epistemológica para a esfera, mais modesta, da interpretação dialógica, seu único fundamento afinal (Bracht e Almeida, 2008).

Os impulsos emancipadores da pedagogia crítica também foram colocados sob suspeita, seja porque já que não estariam, a priori, isentos da vontade de controle e domínio imanentes à constituição da pedagogia moderna, seja porque o próprio conceito de emancipação passou a ser questionado epistemologicamente (o que é emancipar outra pessoa? Tal estado é possível? Uma vez alçando, o que vem depois?) (Sićlia-Camacho e Fernández-Balboa, 2009; Tinning, 2002, 2010).

A pedagogia crítica também foi questionada por ser utópica, abstrata e longa na denúncia, mas escassa na proposição de alternativas concretas capazes de substituir as práticas instituídas (Caparroz, 1997; O'Sullivan, Siendetope Locke, 1992). Desde então, tanto na realidade brasileira quanto no universo anglófono, inúmeras experiências de ensino foram desenvolvidas no sentido de diminuir o hiato entre a teoria e prática crítica. Além de práticas pedagógicas renovadoras e modelos de ensino criticamente orientados, muitas políticas públicas educacionais incorporaram, a seus textos, princípios considerados críticos. ${ }^{7}$ Apesar disso, ainda hoje constitui um desafio de primeira ordem superar aquilo que, metaforicamente, Fensterseifer e González (2007) denominaram "não-mais e aindanão", ou seja, a difícil transição entre uma prática em que não se acredita mais e outra que, por inúmeras razões, ainda tem dificuldade de se implementar. ${ }^{8}$

Outra crítica comum a brasileiros e anglófonos está relacionada aos limites da reflexividade, da conscientização e/ou da racionalidade para se alcançar práticas socialmente críticas na disciplina. Segundo a formulação de Betti (2006), a vertente pedagógica crítica da Educação Física, no esforço de valorizar o discurso filosófico e científico sobre a prática pedagógica, acabou perdendo sua especificidade na medida em que se transformou num discurso sobre aquela prática pedagógica. Essa ação pedagógica, por sua vez, é sempre impregnada da corporeidade do

${ }^{7}$ Muitos referenciais curriculares de Estados, no Brasil, empregam vocabulários e/ou terminologias críticas. Em relação à realidade anglófona, indico a leitura dos seguintes documentos: Health and Physical Education in New Zealand Curriculum (1999) e National Health Physical Education Curriculum for Australia (2014).

${ }^{8}$ Identifico, na literatura anglófona, posições divergentes a respeito deste hiato. Tinning (2018) e outros colegas compreendem que o impacto da pedagogia crítica, apesar de sucessos individuais, ainda é pequeno na intervenção pedagógica. Kirk (2019), por sua vez, considera abstrata e equivocada essa compreensão, contestando-a com exemplos de práticas pedagógicas, currículos e experiências educativas construídas à luz da pedagogia crítica. sentir-se e do relacionar-se, de um "saber orgânico", dimensão que escapa ao saber conceitual e que não pode ser simplesmente alcançada pelo puro pensamento (o saber sobre). A dimensão cognitiva (crítica) do conhecer/compreender far-se-á sempre com base nesse substrato corporal, mas só é possível através da linguagem. Retornar a esse saber orgânico, não enquanto ideia do que dele temos quando o reduzimos a tema do discurso, mas ao que ele é para nós antes de qualquer tematização, é tarefa importante no âmbito das perspectivas críticas. Dito de outro modo, o que Betti (2006) está propondo é a necessidade de resgatar e aprofundar, na teorização crítica da Educação Física, o corpo e/ou o movimento como seus fundamentos primeiros. Não surpreende seu apelo no sentido de voltar ao que chama de Educação Física viva, à sua experiência primordial, que está "[...] onde quer que crianças, jovens, adultos, alunos, professores, atletas, técnicos, clientes ou profissionais - não importam os rótulos - exercitem suas motricidades, relacionem-se e comuniquem-se com o meio e com as pessoas, ensinem e aprendam algo" (Betti, 2007, p. 209).

Bracht (1999, 2012) também reconheceu, com Betti, a ambiguidade acima aludida e o logocentrismo nela pressuposto, dizendo que o saber de que trata a Educação Física tem um duplo caráter: ser um saber que se traduz num saber fazer, num realizar corporal; 2) ser um saber sobre esse realizar corporal. Quando se desconsidera essa ambiguidade, as teorias críticas da Educação Física estão condenadas a falar sobre o corpo e o movimento, correndo o risco de não atingilos. É bastante conhecido o argumento de Bracht (1999, 2012) para que esse quadro seja superado ou, ao menos, mais bem compreendido: precisamos construir uma pedagogia crítica da Educação Física que não seja nem movimento sem pensamento, nem movimento e pensamento, mas sim movimentopensamento. Para tanto, é a própria noção de criticidade que precisa ser revista, já que, no âmbito do discurso sociocrítico, esse conceito foi construído a partir de uma postura racionalista e/ou cognitivista do conhecimento. Seria necessário ampliar essa compreensão, considerando que outras dimensões, como as afetivas, as sensiveis, as estéticas, em suma, outras dimensões corporais também são importantes na definição do comportamento crítico dos indivíduos. Tarefa que não é certamente fácil, conforme demonstram as questões levantadas pelo próprio Bracht (2019, p. 142):

[...] Ou seja, quando falamos em conhecimento na Educação Física falamos apenas do conhecimento conceitual que construímos sobre o corpo em movimento ou é também legítimo falar de outras 
formas de conhecimento (não-discursivas ou préconceituais ou não conceituais) que estão sendo produzidas por esses 'corpos' em movimento? Qual o estatuto deste 'outro' conhecimento, que se manifesta no/pelo/com o movimento? [...] É possível falar em 'pensar com o movimento'? (o que seria muito diferente do que 'pensar sobre o movimento'). Mas, ao invés de utilizar a palavra 'pensar' (muito vinculada à ideia de conhecimento como algo restrito ao plano cognitivo), podemos ampliar para a noção de fazer experiências com o movimento.

Na literatura anglófona, a necessidade de considerar outras dimensões do comportamento humano na definição da tarefa crítica também foi considerada. Gore (1990), há quase trinta anos, alertava para os limites da reflexividade no ensino, o que resultou no reconhecimento dos limites da racionalidade no caminho para a pretendida emancipação. A conclusão é que as razões intelectuais em favor de uma prática crítica são insuficientes para os sujeitos educacionais modificarem suas práticas. Esse reconhecimento parte da compreensão de que a tradição iluminista da pedagogia crítica foi excessivamente racionalista em sua busca pela emancipação e precisaria considerar o que está aquém da reflexividade.

Nesse contexto, Tinning $(2002,2010)$ defenderá a importância de se desenvolver o comprometimento emocional de estudantes e professores, e ao mesmo tempo dirá que seria preciso "incorporar", por assim dizer, as subjetividades. Para fundamentar esse argumento, se apoiará em Dennis Carlson's ao discutir três retóricas, as quais, em sua leitura, constituem a forma básica do diálogo platônico. Elas incluem:

Logos, the analytic voice of critique associated with the truth games of science and philosophy; Thymos, a voice of rage against injustice from the perspective and position of the disempowered, the disenfranchised, and the marginalised; and Mythos, a personal voice of storytelling, cultural mythology, autobiography, and literature (Tinning, 2010, p. 122).

Tinning (2002, 2010) avalia que haveria muitas possibilidades para uma pedagogia crítica que opera a partir dessas três retóricas, sem priorizar o Logos, em detrimento das outras duas retóricas. Thymos e Mythos são tão importantes quanto Logos para envolver alunos e professores em um projeto crítico da disciplina.

Numa direção semelhante à de Tinning, Fitzpatrick e Russel (2015) entendem que a pedagogia crítica tem sido acusada por ser muito "mentalista". Em tais circunstâncias:
What is perhaps needed then is a more embodied and lived approach to critical health and PE, which combines the intensions of critical practice with an understanding of complex embodied experience and connects directly with students; one, possibly, which is more playful and less rational, one which requires us as educators to connect with our students and expose our own place in the hierarchies of power (Fitzpatrick e Russel, 2015, p. 162).

$\mathrm{Na}$ compreensão dos autores, a experiência de vida, a emoção corporal, a estética e os prazeres do movimento deveriam ser pontos de partida do conhecimento socialmente crítico. Em outro artigo, Fitzpatrick (2018) explora a retórica poética (Mythos) como possibilidade de ser "criticamente encarnado". Em sua leitura, a poesia é uma forma corporal de escrita, necessariamente emotiva, sensorial e empática, o que pode propiciar diferentes tipos de compreensão e, ao mesmo tempo, subverter a lógica "racionalista" que interroga o movimento a partir da lógica de um discurso sobre ele. Experienciando o movimento corporal por meio da poesia ou em relação com ela, "[...] the intrinsic experience of subjective movement might be (more effectively) captured, expressed, articulated and narrated. [...] Poiesis and poetic expression offer themselves as vehicles for this self-realisation and expression (Fitzpatrick, 2018, p. 128).

Assim como Tinning e Fitzpatrick, outros colegas da tradição anglófona têm denunciado os "alcances" da racionalidade, insistindo na necessidade de se considerar a existência de um "conhecimento somático" e a importância de outros domínios, como o afetivo, na teoria e na prática da pedagogia crítica (Almeida, 2019).

\section{CONSIDERAÇÕES FINAIS}

O objetivo deste ensaio foi oferecer uma leitura comparada do desenvolvimento da pedagogia crítica da Educação Física em duas realidades, a brasileira e a anglófona, separadas pela língua e pela distância. Partindo de uma problemática comum, tracei algumas analogias, identifiquei semelhanças e diferenças entre esses dois universos. Ao fazer isso, tentei evitar alguns riscos e armadilhas comuns a exercícios comparativos, como a generalização inaceitável ou as analogias forçadas. A expectativa era, por assim dizer, a "iluminação" recíproca e o mútuo aprendizado em relação a este "objeto" comum (a pedagogia crítica).

Apesar do escasso diálogo, não deixa de surpreender a existência de similitudes no desenvolvimento da pedagogia crítica nas literaturas consultadas. $\mathrm{O}$ questionamento da tradição por parte de uma pedagogia adjetivada de crítica ganha fôlego 
a partir dos anos 1980, sendo o campo educacional mais amplo a referência para os pedagogos críticos formularem suas críticas. Essas afinidades também se manifestam em algumas (auto)críticas produzidas contra a pedagogia crítica, bem como nas renovações propostas em seu âmbito.

Malgrado essas aproximações, também identifiquei diferenças. Se, no Brasil, predominou, embora não exclusivamente, uma pedagogia marxista nas formulações iniciais da pedagogia crítica, o mesmo não se pode afirmar em relação à tradição anglófona. Também a metodologia da pesquisa-ação constituiu uma perspectiva recorrente na literatura anglófona quando do seu surgimento, situação que não se verificou no Brasil. Além disso, entre Paulo Freire e Dermeval Saviani, a pedagogia crítica da Educação Física, no Brasil, "preferiu" o segundo, no âmbito da literatura aqui comparada, Paulo Freire ainda hoje é uma referência central.

A descrição realizada também revelou que a pluralidade teórica e, consequentemente, política, é marca importante do discurso sociocrítico na Educação Física nos dois universos estudados. Muitos autores da literatura anglófona, ao empregarem o conceito de "big tent", prescindiram de oferecer uma delimitação mais precisa da pedagogia crítica após o impacto da dúvida pós-moderna. Ampliaram, por assim dizer, seu significado e incorporaram perspectivas teóricas nem sempre convergentes. No Brasil, identifiquei três consequências da incredulidade "pós" e da pluralidade desencadeada. Duas delas guardam relação com o que se passou no universo anglófono; quer dizer, uma delas resulta na incorporação de temas "pós" a agenda emancipatória da disciplina; a outra, ainda incipiente, advoga em favor de uma pedagogia pós-crítica. Por fim, a reação "conservadora" à dúvida "pós" é marca tipicamente nacional, influência de uma pedagogia marxista, que ainda ecoa na tradição crítica da área.

\section{REFERÊNCIAS}

Bracht V, Almeida FQ. Pedagogia crítica da educação física: dilemas e desafios na atualidade. Movimento, v. 25, e25001, 2019, p. 1-15.

Bracht $V$ et al. A Educação Física Escolar como tema da produção do conhecimento nos periódicos da área no Brasil (19802010): parte II. Movimento, v. 18, n. 2, 2012, p. 11-37.

Almeida FQ, Bracht V, Vaz AF. Educação Física, pedagogia crítica e ideologia. Movimento 2015; 21 (2): 317-331.

Betti M. Corpo, motricidade e cultura: a fundação pedagógica da educação física sob uma perspectiva fenomenológica e semiótica. 2006. Relatório de pesquisa apresentado ao Departamento de Educação Física da Faculdade de Ciências. Bauru, 2006.

Bracht V. A criança que pratica esportes respeita as regras do jogo... capitalista. Revista Brasileira de Ciências do Esporte 1986; 7 (2): 62-68.
Bracht V. A Educação Física escolar no Brasil: o que ela vem sendo e o que pode ser (elementos de uma teoria pedagógica para a Educação Física). Ijuí: Unijuí; 2019.

Bracht V, Almeida FQ. O debate Rorty/Habermas: implicações para a relação entre a teoria e a prática pedagógica na Educação Física. Revista. Brasileira de Ciências do Esporte 2008; 29 (3): 123-136.

Burbules NC. As dúvidas pós-modernas e a filosofia da educação. In: Ghiraldelli Júnior P. O que é filosofia da educação. Rio de Janeiro: DP\&A; 2000. 121-137

Caparroz FE. Entre a educação física na escola e a educação física da escola. Vitória: CEFD-UFES; 1997

Devís-Devís J. Socially critical research perspectives in physical education. The Handbook of Physical Education. In Kirk D, Macdonald D, O'Sullivan M. London: Sage; 2006. p. 37-58.

Fensterseifer P, Gonzalez, FJ. Educação Física escolar: a difícil e incontornável relação teoria e prática. Motrivivência 2007; XIX (28): 27-37.

Fitzpatrick K, Russell D. On being critical in health and physical education, Physical Education and Sport Pedagogy 2015; 20 (2): 159-173.

Fitzpatrick K. Poetry in motion: in search of the poetic in health and physical education, Sport, Education and Society, 2018; 23 (2): 123-134.

Gamboa S. O debate da pós-modernidade: as teorias do conhecimento em jogo. Filosofia e Educação: Revista Digital do Paidéia 2010; 2 (2): 74-98.

George L, Kirk D. The limits of change in Physical Education: ideology, teachers and the experience of physical activity. In: Evans J. Teachers, teaching and control in Physical Education. Falmer Press: Philadelphia; 1988. p. 145-155.

Gore J M. Pedagogy as text in physical education teacher education: Beyond the preferred reading. In: Kirk D, Tinning R. Physical education, curriculum and culture: critical issues in the contemporary crisis. London: The Falmer Press; 1990. p. 101-138.

Kirk D. A critical pedagogy for teacher education: Towards an inquiry-oriented approach. Journal of Teaching in Physical Education 1986; 5 (4): 230-246.

O'Sullivan M, Siedentop D, Locke L. Toward collegiality: competing viewpoints among teacher educators. Quest 1992; 44 (2): 266-280.

Paraíso MA. Pesquisas pós-críticas em educação no Brasil: esboço de um mapa. Cadernos de Pesquisa 2004; 34 (122): 283-303.

Rigo LC, Chagas EP. Educação física escolar e reprodução social. Revista Brasileira de Ciências do Esporte 1990; 11 (3): 179-185.

Sicília-Camacho A, Fernández-Balboa JM. Reflecting on the moral bases of critical pedagogy in PETE: toward a foucaultian perspective on ethics and the care of the self. Sport, Education and Society 2009; 14 (4): 443-463.

Taffarel CNZ, Albuquerque A. Epistemologias e teorias do conhecimento em educação e educação física: reações aos pós-modernismos. Filosofia e Educação: Revista Digital do Paidéia 2010; 2 (2): 8-52.

Tinning R. Physical Education and the cult of slenderness. ACHPER National Journal, 1985; 107: 10-13.

Wright J. Postmodern, poststructural and postcolonial research in physical education. In: Kirk D, Macdonald D, O'Sullivan M. Handbook of Physical Education. London: Sage; 2006. p. 59-76. 